\title{
Utilização do subproduto da recuperação metálica de escórias de aços inoxidáveis na síntese de pigmentos cerâmicos; caracterização da matéria-prima
}

\section{(By-product utilization of metallic recovering of stainless steel slags in the ceramic pigments synthesis; raw material characterization)}

\author{
V. P. Della , J. A. Junkes ${ }^{1}$, I. Kuhn ${ }^{1}$, H. G. Hiella', D. Hotza ${ }^{2}$ \\ ${ }^{1}$ Departamento de Engenharia Mecânica, ${ }^{2}$ Departamento de Engenharia Química \\ Universidade Federal de Santa Catarina \\ C.P. 476, Florianópolis, SC 88040-900 \\ viviana@pg.materiais.ufsc.br
}

\begin{abstract}
Resumo
O processo de recuperação metálica em escórias de aciaria - resíduo gerado em grande quantidade no processo de refino do ferro-gusa para obtenção do aço - que visa a recuperação de metais nobres, gera uma massa de óxidos que pode ser utilizada como fonte precursora na síntese do pigmento cerâmico verde vitória. Verde vitória é o nome dado ao pigmento cerâmico à base de cálcio, cromo e silício $\left(\mathrm{Ca}_{3} \mathrm{Cr}_{2} \mathrm{Si}_{3} \mathrm{O}_{12}\right) \mathrm{que}^{\mathrm{a}}$ elevadas temperaturas desenvolve a estrutura cristalina uvarovita responsável pela estabilização da cor verde característica. Este subproduto apresenta características constitucionais favoráveis à obtenção deste pigmento mediante o ajuste da composição química através da adição de óxidos puros. A combinação de técnicas de análise microestrutural, térmica e química foi utilizada nesta caracterização inicial.

Palavras-chave: escória de aciaria, pigmento cerâmico, verde vitória, uvarovita.
\end{abstract}

\begin{abstract}
The metallic recovering process of steel industry slags - waste produced in a big amount by the process of pig iron refining for steel obtainment, which aims the recovering of noble metals, produces a oxide mass that can be used as a precursor source for the synthesis of the Victory Green ceramic pigment. Victory Green is the name of the ceramic pigment based on calcium, chromium and silicon $\left(\mathrm{Ca}_{3} \mathrm{Cr}_{2} \mathrm{Si}_{3} \mathrm{O}_{12}\right)$, and that develops the uvarovite crystalline structure in high temperatures, responsible for the stabilization of characteristic green color. This by-product presents favorable constitutional characteristics to the obtainment of this pigment by adjusting the chemical composition through additions of pure oxides. The combination of techniques of microstructural, thermal and chemical analysis was used in this initial characterization.

Keywords: Steel industry slags, ceramic pigment, victoria green, ceramic pigment, uvarovite.
\end{abstract}

\section{INTRODUÇÃO}

No contexto de equilíbrio no consumo e na conservação de recursos minerais, energéticos e ambientais, a reciclagem exerce um importante papel na economia de jazidas escassas de matériaprima bruta, na diminuição da poluição indiscriminada e no racionamento de energia, transformando uma fonte importante de despesas em uma fonte de faturamento ou, pelo menos, de redução das despesas de deposição.

As escórias de aciaria são resíduos da produção do aço, compostas basicamente por $\mathrm{SiO}_{2}, \mathrm{CaO}, \mathrm{Al}_{2} \mathrm{O}_{3}, \mathrm{MgO}, \mathrm{MnO}$, $\mathrm{Fe}_{2} \mathrm{O}_{3}, \mathrm{Cr}_{2} \mathrm{O}_{3}$, carbono, dentre outros, com grande geração anual e que pouca destinação obtém [1].

Considerando que em cada tonelada de aço produzido são geradas cerca de $150 \mathrm{~kg}$ de escória de aciaria, o Brasil com uma produção de 31,1 milhões de toneladas gerou somente no ano de 2003 aproximadamente 4,6 milhões de toneladas deste resíduo.
Devido a esse elevado volume gerado anualmente, surgiu a necessidade do desenvolvimento de novos produtos com potencial de vendas, visando minimizar o impacto ambiental oriundo do depósito deste em aterros [1,2].

Além das possibilidades de aproveitamento citadas, as escórias de aciaria podem ser submetidas a um processo que busca recuperar ao máximo os metais contidos, visando sua reutilização na produção do aço, reduzindo assim o custo das matérias-primas e evitando exploração de recursos naturais. Deste processo de recuperação metálica, obtém-se um subproduto com aplicação econômica.

Todas as escórias de aciaria podem ser recuperadas metalicamente, porém, o subproduto empregado neste trabalho é resultante do processo de recuperação em escórias de aços inoxidáveis. O subproduto, escória de aço inoxidável após recuperação metálica, é atualmente usado na pavimentação de estradas vicinais e como fertilizante na agricultura, porém, a 
quantidade empregada ainda está abaixo do volume de escória gerado, restando uma grande parcela em estoque no pátio das empresas. Com o crescente desenvolvimento científico, comprova-se a viabilidade de utilização das escórias de aciaria em diversas áreas da engenharia, como por exemplo na obtenção de vidros, vitrocerâmicos, revestimentos cerâmicos, brita siderúrgica, etc. [1, 3-5].

A fabricação de pigmentos cerâmicos é uma aplicação nobre, nesse sentido. O custo relativamente alto desse tipo de processo seria em parte compensado pelo alto valor agregado do produto final e pelo baixo custo da matériaprima, sem falar da economia que se faz devido à eliminação da necessidade de armazenamento e descarte desse resíduo em áreas específicas.

Pigmentos são substâncias no estado sólido, orgânicas ou inorgânicas, que consistem de pequenas partículas insolúveis no meio ao qual venham a ser aplicadas e com o qual não interaja física nem quimicamente [6,7].

Com o intuito de desenvolver pigmentos que substituam outros já conhecidos em resposta a motivações econômicas, sanitárias e ambientais, diferentes tipos de resíduos estão sendo utilizados em estudos que visam a obtenção de novos pigmentos cerâmicos. Com o avanço das pesquisas está sendo possível a incorporação de resíduos de diferentes composições químicas, tais como resíduos das indústrias siderúrgicas, borra de níquel, cobalto, zinco, cromo, metal duro, lodos de estações de tratamento, etc. Tais resíduos possuem em sua composição determinados elementos de significativa importância para a composição de pigmentos, obtendo-se uma ampla variedade de cores apreciadas pelo mercado de revestimentos cerâmicos [8]. Como exemplo desta linha de pesquisa, foram realizados estudos que possibilitaram a incorporação de resíduos de galvanoplastia na produção de um pigmento cerâmico à base de ferro, cromo e zinco, com características de cor e estabilidade térmica apreciáveis [9].

Neste trabalho, pretende-se obter o pigmento cerâmico conhecido como verde vitória, constituído por compostos à base de cálcio, cromo e silício, geralmente na forma de óxidos que desenvolvem, mediante tratamento térmico, a estrutura cristalina uvarovita. Pigmentos à base de cromo apresentam uma ampla variedade de amarelos, laranjas e verdes com altas estabilidades térmica e química, são muito requeridos pela indústria cerâmica.

Para a obtenção deste pigmento, pode ser utilizado o método cerâmico de mistura de pós e o método sol-gel. Pelo método cerâmico, os compostos precursores mais utilizados são óxido de cálcio, carbonato de cálcio, bicromato de potássio, óxido de cromo (III), diatomita, quartzo e sílica amorfa. Pelo método sol-gel, sais de cálcio e cromo na forma de nitratos e cloretos, alcóxido de silício - tetraetilortosilicato (TEOS) e sílica coloidal são utilizados [10-16].

Devido a investigações prévias, este pigmento pode ser sintetizado em uma faixa de temperatura de $700{ }^{\circ} \mathrm{C}$ a $1400{ }^{\circ} \mathrm{C}$, com patamares de queima de $1 \mathrm{~h}$ a $15 \mathrm{~h}$, dependendo do método de síntese, com limite de estabilidade em torno de
$1370{ }^{\circ} \mathrm{C} \pm 10^{\circ} \mathrm{C}$, a partir do qual dissocia-se em $\alpha-\mathrm{CaSiO}_{3} \mathrm{e}$ $\mathrm{Cr}_{2} \mathrm{O}_{3} \cdot[12,17]$

Desta forma, este trabalho propõe a caracterização do subproduto da recuperação metálica em escórias de aços inoxidáveis para aplicação na síntese do pigmento cerâmico verde vitória com a devida correção da composição química pela adição de óxidos puros.

\section{MATERIAIS E MÉTODOS}

A escória de aços inoxidáveis, submetida à recuperação metálica (cromo, ferro, alumínio, etc.) é oriunda da Companhia Aços Especiais Itabira - ACESITA (Timóteo, MG). O subproduto recuperado metalicamente a partir desta escória foi cedido pela empresa Recmix S/A (Timóteo, MG) responsável pelo processo de recuperação.

O teste de lixiviação foi realizado de acordo com as condições exigidas pela norma NBR 10005 [18]. Para classificação do resíduo foi utilizada a listagem $\mathrm{n}^{\circ} 7$, contida na NBR 10004 [19].

O teste de solubilização foi conduzido conforme a norma NBR 10006 [20]. Os resultados obtidos foram comparados à listagem $n^{\circ}$ 8, contida na NBR 10004 [19].

Para a realização da medida colorimétrica do subproduto foi utilizado um espectrofotômetro HunterLab, modelo ColorQuest de geometria $45^{\circ} / 0^{\circ}$ com fonte de iluminação D65 e ângulo de observação padrão $10^{\circ}$. Como escala de leitura colorimétrica adotou-se o sistema de coordenadas cromáticas L* $\mathrm{a}^{*} \mathrm{~b} *$ da CIE (Commission Internationale de I’Eclairage - Comissão Internacional de Iluminação).

O percentual de cada constituinte do subproduto foi determinado através da técnica de fluorescência de raios X (Phillips, modelo PW 2400). Para a detecção das fases cristalinas foi empregada a técnica de difração de raios $\mathrm{X}$ em difratômetro Phillips modelo Xpert, com tubo de $\mathrm{Cu}$ $(K \alpha)$. Para a caracterização microestrutural, as amostras observadas em microscópio eletrônico de varredura (Phillips, modelo XL 30). A distribuição do tamanho de partículas foi determinada usando a técnica de difratometria a laser em equipamento Cilas (modelo 1064L).

\section{RESULTADOS E DISCUSSÃO}

Para a reutilização e reciclagem de resíduos como materiais efetivos, a maioria deles, muitas vezes, necessita de extensivas operações de separação de contaminantes. Estes processos, inevitavelmente, consomem energia e produzem seus próprios efeitos ambientais. Estes efeitos são por vezes diferentes qualitativa e quantitativamente dos efeitos do produto primário processado. Portanto, é necessário fazer uma avaliação compreensiva dos prováveis efeitos ambientais trazidos pelo processo primário e pela rota de reciclagem antes da implementação de algum tipo de reciclagem.

Fazendo parte da caracterização ambiental do subproduto, a Tabela I contém a análise da solução proveniente do ensaio 
Tabela I - Ensaio de lixiviação do subproduto. [Table I - Leaching test of the by-product.]

\begin{tabular}{ccc}
\hline Parâmetros & $\begin{array}{c}\text { Concentração } \\
(\mathrm{mg} / \mathrm{L})\end{array}$ & $\begin{array}{c}\text { Limite máximo } \\
\text { permitido no } \\
\text { extrato }(\mathrm{mg} / \mathrm{L})\end{array}$ \\
\hline Arsênio & $\mathrm{ND}$ & 5,00 \\
Cádmio & $\mathrm{ND}$ & 0,50 \\
Chumbo & $\mathrm{ND}$ & 5,00 \\
Cromo Total & 0,17 & 5,00 \\
Mercúrio & ND & 0,10 \\
Bário & ND & 100,00 \\
Selênio & ND & 0,10 \\
Prata & ND & 5,00 \\
Fluoreto & ND & 150,00 \\
\hline
\end{tabular}

(ND) Não detectado.

de lixiviação, e a Tabela II contém a análise da solução submetida ao ensaio de solubilização.

Para o extrato de lixiviação, apenas cromo foi detectado, estando o valor deste $(0,17 \mathrm{mg} / \mathrm{L})$ bem abaixo do valor máximo de $5 \mathrm{mg} / \mathrm{L}$ permitido pela legislação vigente. Conforme o resultado apresentado, o subproduto não é considerado um resíduo tóxico. Assim como no extrato de lixiviação, cromo também foi detectado no extrato de solubilização, porém, o valor detectado $(0,11 \mathrm{mg} / \mathrm{L})$ excede o valor máximo de $0,05 \mathrm{mg} / \mathrm{L}$ permitido.

Segundo especificações da NBR-10004 [19], para que um resíduo seja considerado classe III-inerte, o mesmo não deve apresentar nenhum dos seus constituintes solubilizados em concentrações superiores aos padrões de potabilidade da água, conforme listagem $\mathrm{n}^{\circ} 8$, excetuando-se os padrões de aspecto, cor, turbidez e sabor. Caso esta condição não seja obtida, o resíduo analisado será classificado como classe II-não inerte.

Analisando os resultados apresentados pelos ensaios de lixiviação e solubilização, o subproduto foi classificado como resíduo de classe II-não inerte. Devido a esta classificação, este resíduo deve ser tratado antes da sua disposição final para que seja impedida a contaminação do meio ambiente. Levando em conta que este subproduto seja usado na composição de pigmento, após tratamento a altas temperaturas pelo método cerâmico, e que sua concentração relativa no produto final diminua consideravelmente, esta pode ser uma aplicação satisfatória sob o ponto de vista ambiental. Além do aspecto ambiental, justifica-se esse emprego economicamente, já que o resíduo seria empregado como alternativa ao óxido de cromo sintético, de alto custo. Quanto ao tratamento dos resíduos do processo de fabricação do pigmento, estes são tratados da mesma forma que um pigmento feito a partir de matérias-primas puras convencionais, não agregando maiores custos ou impactos ambientais ao processamento.

As coordenadas colorimétricas $\mathrm{L}^{*} \mathrm{a}^{*} \mathrm{~b}^{*}$ foram obtidas com base no espaço de cor CIELAB, onde $\mathrm{L}^{*}$ é uma indicação de claro e escuro, a* é uma indicação de tonalidade
Tabela II - Ensaio de solubilização do subproduto. [Table II - Solubilization test of the by-product.]

\begin{tabular}{|c|c|c|}
\hline Parâmetros & $\begin{array}{c}\text { Concentração } \\
(\mathrm{mg} / \mathrm{L})\end{array}$ & $\begin{array}{l}\text { Limite máximo } \\
\text { permitido no } \\
\text { extrato }(\mathrm{m} / \mathrm{L})\end{array}$ \\
\hline Alumínio & ND & 0,20 \\
\hline Chumbo & ND & 0,05 \\
\hline Cromo total & 0,11 & 0,05 \\
\hline Ferro & $<0,1$ & 0,30 \\
\hline Manganês & $<0,1$ & 0,10 \\
\hline Zinco & ND & 5,00 \\
\hline Dureza $\left(\mathrm{CaCO}_{3}\right)$ & 10 & 500,00 \\
\hline Fenol & ND & 0,01 \\
\hline Bário & ND & 1,00 \\
\hline Arsênio & ND & 0,05 \\
\hline Cádmio & ND & 0,005 \\
\hline Selênio & ND & 0,01 \\
\hline Cobre & $<0,1$ & 0,10 \\
\hline Mercúrio & ND & 0,001 \\
\hline Nitrato $(\mathrm{N})$ & ND & 10,00 \\
\hline Fluoreto & ND & 1,50 \\
\hline Cianetos & ND & 0,10 \\
\hline Sulfatos & ND & 400,00 \\
\hline Cloretos & ND & 250,00 \\
\hline Sódio & ND & 200,00 \\
\hline Surfactantes & ND & 0,01 \\
\hline
\end{tabular}

(ND) Não detectado.

na direção do verde $\left(-a^{*}\right)$ para o vermelho $\left(+a^{*}\right)$ e b* é uma indicação de tonalidade na direção do azul $\left(-b^{*}\right)$ para o amarelo $\left(+b^{*}\right)$. Obteve-se como coordenadas colorimétricas para o subproduto: $\mathrm{L}^{*}=57,52, \mathrm{a}^{*}=0,40$ e $\mathrm{b}^{*}=5,85$. A combinação destas coordenadas indica que o subproduto é constituído por uma mistura de vermelho e amarelo. Porém, devido aos valores serem relativamente baixos (baixa saturação), a tonalidade resultante é cinza, tendendo a cinza claro.

A Tabela III apresenta o resultado da análise química por fluorescência de raios $\mathrm{X}$ de três amostras representativas do subproduto em estudo, a qual detectou como compostos majoritários os óxidos de cálcio, silício e magnésio.

Segundo a literatura pertinente $[12,15,21,22]$, a composição química do pigmento cerâmico verde vitória é baseada na estequiometria da fase cristalina uvarovita $\left(\mathrm{Ca}_{3} \mathrm{Cr}_{2} \mathrm{Si}_{3} \mathrm{O}_{12}\right)$ apresentada na Tabela IV; desta forma, pode-se observar pela comparação com a análise química apresentada na Tabela III, que os elementos de interesse (Ca, $\mathrm{Cr}$ e $\mathrm{Si}$ ) estão presentes e em quantidades apreciáveis para o objetivo proposto. O restante dos elementos presentes, por não participarem da composição química do pigmento, será identificado como impurezas, as quais poderão atuar de forma positiva ou negativa na formação deste durante a etapa de calcinação, bem como no desenvolvimento da cor durante a queima do esmalte. Essas etapas, porém, não serão avaliadas neste trabalho inicial. 
Conforme apresentado na Tabela III, o percentual de $\mathrm{Cr}_{2} \mathrm{O}_{3}$ e $\mathrm{SiO}_{2}$ contido no subproduto está abaixo do necessário. De acordo com o percentual destes a ser adicionado em cada formulação, a mesma será corrigida com a adição de óxidos puros, atingindo assim a estequiometria requerida. O resultado da análise química apresenta os elementos na forma de óxidos. No entanto, estes podem estar combinados de forma diferente.

A Fig. 1 apresenta o difratograma de raios $\mathrm{X}$ do subproduto. Nota-se que este apresenta alto nível de ruído, com baixa contagem $(<600)$, mostrando apenas uma tendência dos elementos presentes no subproduto. Verificase também um halo característico de região amorfa. A baixa cristalinidade do material pode ser resultante do rápido resfriamento ao qual o subproduto foi submetido após ser separado do metal. Pela análise do difratograma, foram identificadas as seguintes fases: silicato de sódio - $\mathrm{Ca}_{2} \mathrm{SiO}_{4}$ (JCPDS 31-0297), mervinita - $\mathrm{Ca}_{3} \mathrm{Mg}\left(\mathrm{SiO}_{4}\right)_{2}$ (JCPDS 350591), gehlenita - $\mathrm{Ca}_{2} \mathrm{Al}_{2} \mathrm{SiO}_{7}$ (JCPDS 20-0199) e enstatita - (Mg,Fe) $\mathrm{SiO}_{3}$ (JCPDS 19-0605).

Quando analisado macroscopicamente, Fig. 2, o subproduto empregado nesta caracterização apresenta coloração cinza claro também evidenciada pela análise colorimétrica. Pode-se verificar, ainda, que o mesmo é composto por partículas aglomeradas e dispersas.

Observa-se na Fig. 3 que o subproduto analisado apresenta morfologia heterogênea, com partículas irregulares de tamanhos variados $(0,3 \mathrm{a} \sim 1,5 \mathrm{~mm})$.

O resultado do ensaio de distribuição granulométrica pode ser observado na Fig. 4. Verifica-se que $100 \%$ das partículas estão abaixo de $36,0 \mu \mathrm{m}, 90 \%$ abaixo de $15,8 \mu \mathrm{m}$ e $50 \%$ abaixo de 3,9 $\mu \mathrm{m}$. Conclui-se que as partículas do subproduto são na verdade aglomerados de partículas menores, muito abaixo dos tamanhos de partículas observados por

Tabela III - Composição química do subproduto.

[Table III - By-product chemical composition.]

\begin{tabular}{cc}
\hline Óxidos & $\begin{array}{c}\text { \% em Massa } \\
\text { (Média } \pm \text { Desvio padrão) }\end{array}$ \\
\hline $\mathrm{CaO}$ & $35,85 \pm 0,96$ \\
$\mathrm{SiO} \mathrm{O}_{2}$ & $28,05 \pm 1,67$ \\
$\mathrm{MgO}$ & $12,34 \pm 0,41$ \\
$\mathrm{Fe}_{2} \mathrm{O}_{3}$ & $6,47 \pm 0,38$ \\
$\mathrm{Al}_{2} \mathrm{O}_{3}$ & $5,25 \pm 0,25$ \\
$\mathrm{Cr}_{2} \mathrm{O}_{3}$ & $3,00 \pm 0,24$ \\
$\mathrm{MnO}$ & $1,12 \pm 0,04$ \\
$\mathrm{TiO}_{2}$ & $0,41 \pm 0,00$ \\
$\mathrm{P}_{2} \mathrm{O}_{5}$ & $0,24 \pm 0,07$ \\
$\mathrm{ZrO}_{2}$ & $0,05 \pm 0,09$ \\
$\mathrm{~K}_{2} \mathrm{O}$ & $0,13 \pm 0,02$ \\
$\mathrm{SrO}$ & $0,10 \pm 0,01$ \\
$\mathrm{Na}_{2} \mathrm{O}$ & $0,08 \pm 0,02$ \\
Perda ao fogo & $6,91 \pm 0,56$ \\
Total & 100,00 \\
\hline
\end{tabular}

Tabela IV - Composição estequiométrica dos óxidos presentes no pigmento verde vitória.

[Table IV - Stoichiometric composition of the oxides in the victoria green ceramic pigment.]

\begin{tabular}{cc}
\hline Precursores & \% em Massa \\
\hline $\mathrm{CaO}$ & 33,61 \\
$\mathrm{Cr}_{2} \mathrm{O}_{3}$ & 30,37 \\
$\mathrm{SiO}_{2}$ & 36,02 \\
$\mathrm{Total}^{2}$ & 100,00 \\
\hline
\end{tabular}

microscopia eletrônica de varredura (Fig. 3).

Segundo a referência [23], é necessário controlar a granulometria dos precursores utilizados para evitar partículas de tamanho superior a $45 \mu \mathrm{m}$, pois estas favorecem a aglomeração, dificultando as reações durante a calcinação.

A Fig. 5 apresenta a distribuição granulométrica dos óxidos puros utilizados na correção da composição. No óxido de cromo III, $100 \%$ das partículas estão abaixo de $18,0 \mu \mathrm{m}, 90 \%$ abaixo de $5,9 \mu \mathrm{m}$ e $50 \%$ com tamanho médio abaixo de $1,5 \mu \mathrm{m}$. O carbonato de cálcio apresentou $100 \%$ das partículas abaixo de 15,0 $\mu \mathrm{m}, 90 \%$ abaixo de $6,2 \mu \mathrm{m}$ e $50 \%$ com tamanho médio inferior a 2,6 $\mu \mathrm{m}$. O óxido de silício apresentou distribuição granulométrica mais ampla com $100 \%$ das partículas abaixo de $45,0 \mu \mathrm{m}, 90 \%$ abaixo de $26,7 \mu \mathrm{m}$ e $50 \%$ abaixo de $14,1 \mu \mathrm{m}$.

Na Fig. 6 encontram-se os difratogramas de raios $X$ correspondentes aos óxidos utilizados na correção da composição estequiométrica do pigmento. Nota-se que tanto o óxido de cromo III como o carbonato de cálcio estão isentos de impurezas. O óxido de silício apresenta-se na forma predominantemente amorfa, com pequena contaminação por sulfato de sódio $\mathrm{Na}_{2} \mathrm{SO}_{4}$ (JCPDS 24-1132).

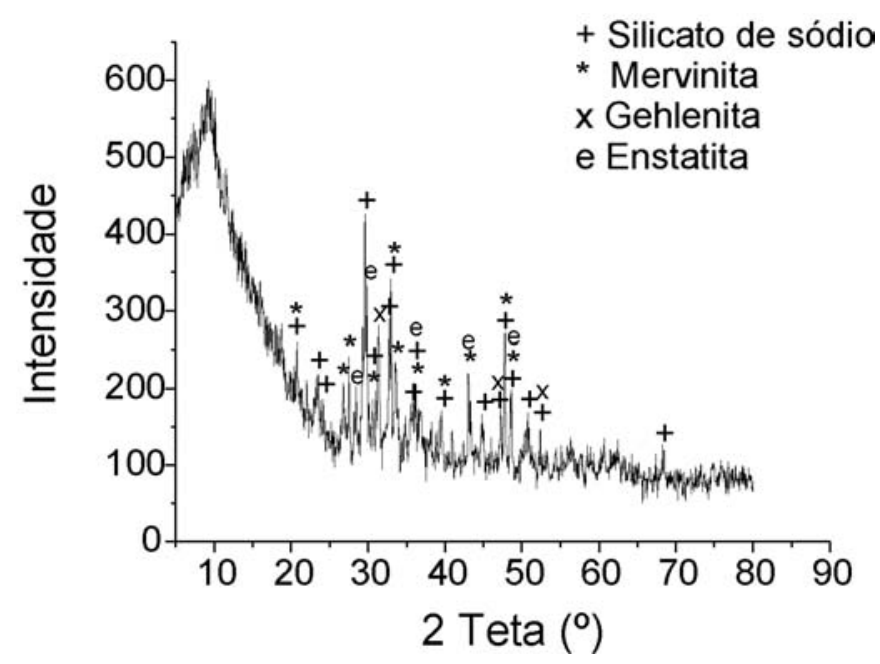

Figura 1: Difratograma de raios $\mathrm{X}$ do subproduto. [Figure 1: X-ray diffraction pattern of the by-product.] 


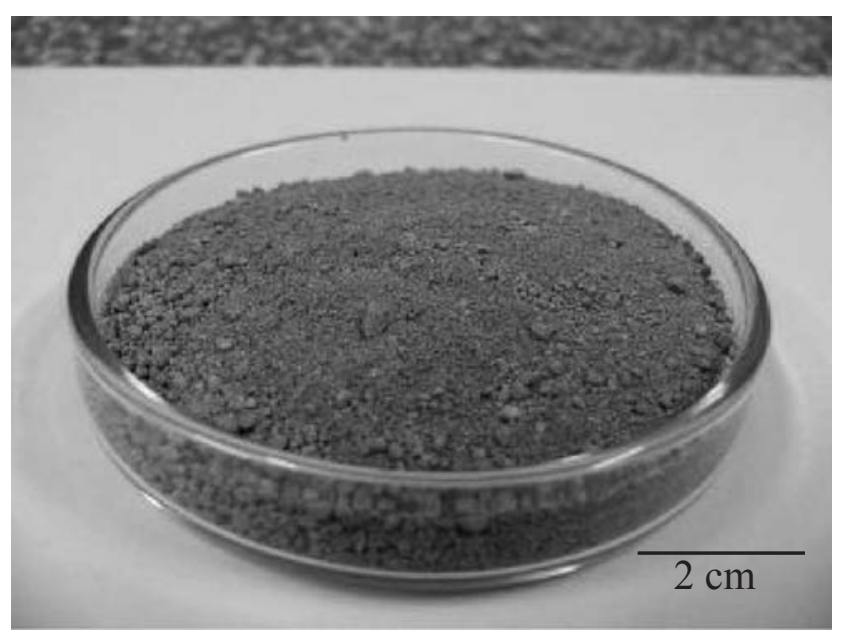

Figura 2: Subproduto in natura.

[Figure 2: In natura by-product.]

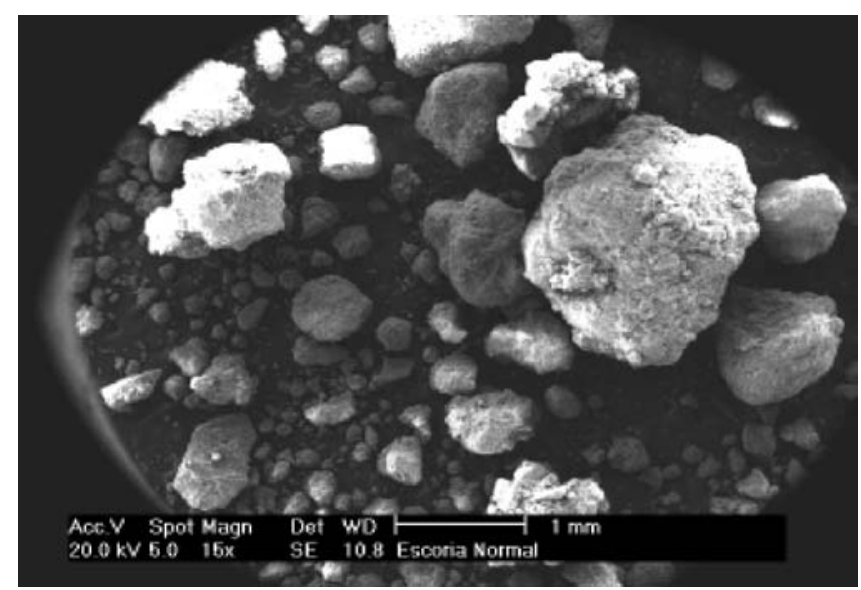

Figura 3: Microscopia eletrônica de varredura do subproduto.

[Figure 3: Scanning electron microscopy micrograph of the by-product].

\section{CONCLUSÕES}

A utilização do subproduto da recuperação metálica em escórias de aço inoxidável é justificada por razões de ordem tecnológica, econômica e ecológica. No âmbito tecnológico está o fato deste resíduo apresentar elementos químicos tais como cromo, cálcio e silício em quantidades significativas que podem ser usados na manufatura de vários materiais, dentre estes, pigmentos cerâmicos. A razão econômica baseia-se no reaproveitamento de um resíduo com apreciável valor econômico a princípio descartado. E a razão ecológica relaciona-se com a alternativa de disposição final mais sustentável ambientalmente deste resíduo, visando reduzir o passivo ambiental com a geração de um novo produto de maior valor agregado.

Neste trabalho, revelou-se a potencialidade de emprego do subproduto da recuperação metálica em escórias de aço inoxidável na obtenção de pigmentos cerâmicos a base de cromo. Pelas análises de lixiviação e solubilização, o subproduto é classificado como não inerte. Considerando o seu emprego como umas das matérias-primas na composição do pigmento,

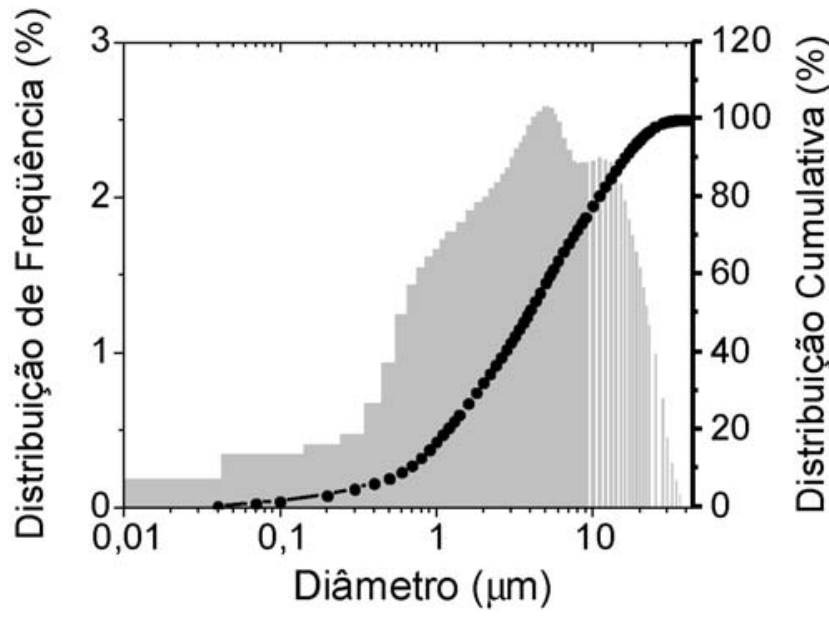

Figura 4: Distribuição de tamanho de partículas do subproduto. [Figure 4: Particle size distribution of the by-product.]

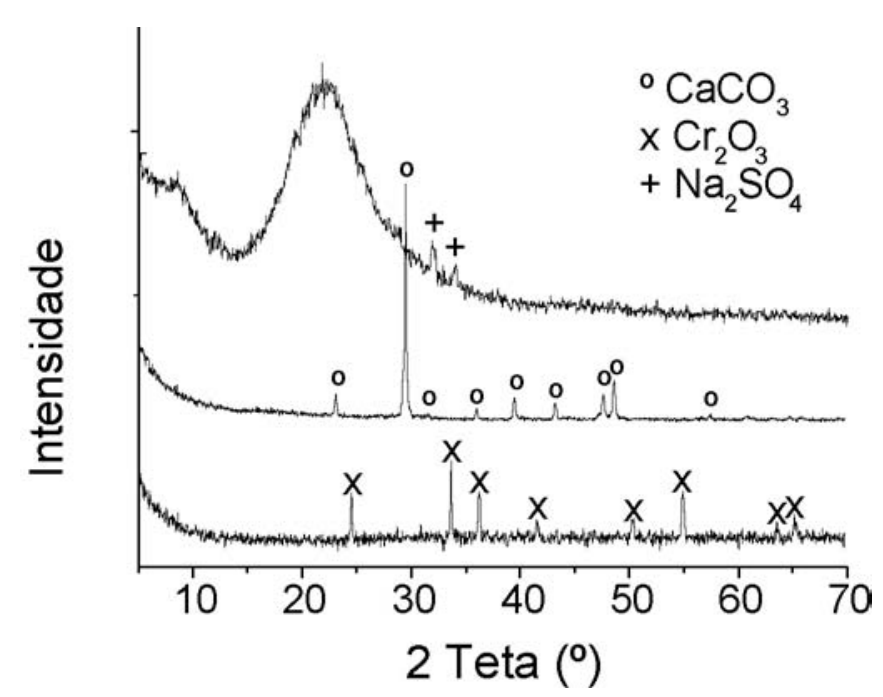

Figura 6: Difratogramas de raios $\mathrm{X}$ dos óxidos puros.

[Figure 6: X-ray diffraction patterns of the pure oxides.]

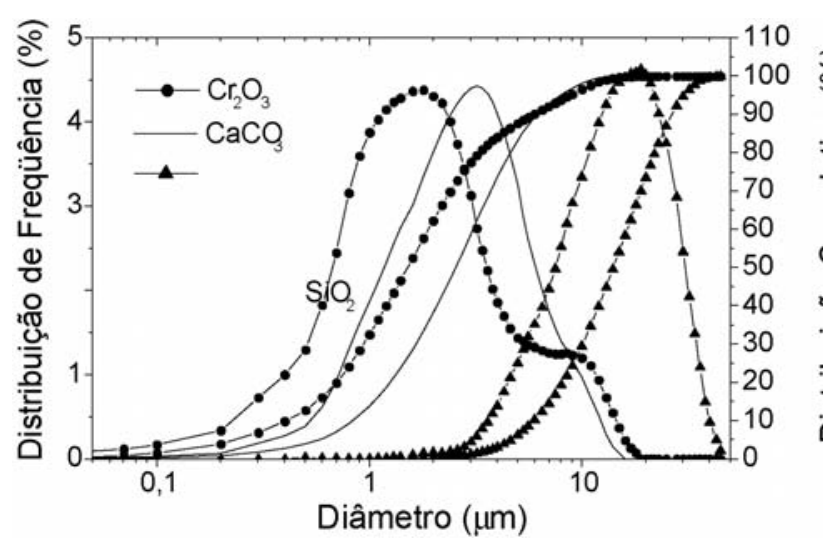

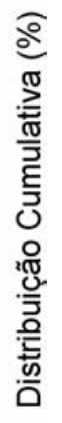

Figura 5: Distribuição de tamanho de partículas dos óxidos puros. [Figure 5: Particle size distribution of the pure oxides.] 
sua concentração relativa seria reduzida a níveis aceitáveis, comparáveis aos pigmentos já fabricados a partir de matériasprimas sintéticas.

As tonalidades detectadas para o subproduto poderão ser alteradas pela interação com os demais componentes da mistura precursora do pigmento, após o tratamento térmico típico do método cerâmico a ser empregado. A composição química das matérias-primas, tanto resíduos quanto materiais sintéticos, e sua distribuição granulométrica estão dentro dos padrões aceitáveis para fabricação de pigmentos cerâmicos.

Industrialmente, há uma grande preocupação quanto à utilização de resíduos na formulação de pigmentos cerâmicos devido a problemas de homogeneidade no processamento. Porém, é possível a realização de ajustes de composição, por meio da adição de outros componentes, da mesma forma que é realizado nos colorifícios.

\section{AGRADECIMENTOS}

Os autores desejam externar os seus agradecimentos à Colorminas Pigmentos e Colorifício, pela parceria na realização dos ensaios de aplicação das peças, e ao $\mathrm{CNPq}$ pelo auxílio financeiro na forma de bolsa de doutorado.

\section{REFERÊNCIAS}

[1] L. John, Pesquisa cria alternativa para reciclagem do rejeito de siderúrgicas, http://www.geoklock.com.br/nrws/ noticias/20020808.html, acessado em 10/03/2004.

[2] COSIPA, Companhia Siderúrgica Paulista, http:// www.cosipa.com.br/mercados>, acessado em 20/03/2004.

[3] R. T. Geyer, Dal Molin, A. C. F. Vilele, Anais do $51^{\circ}$ Congresso Anual da ABM, Porto Alegre, RS (1996) 305-314.

[4] E. B. Ferreira, E. D. Zanotto, L. A. M. Scudeller, Química Nova 25 (2002) 731-35.

[5] M. A. Magella, Desenvolvimento de materiais vítreos e vitrocerâmicos a partir de escórias da produção de aços inoxidáveis, Universidade Federal de Santa Catarina,
Dissertação, Florianópolis, SC (1999) 66 p.

[6] K. Nassau, The Physics and Chemistry of Color, $1^{\text {a }}$ ed., John Wiley \& Sons, New York (1983) 291.

[7] F. Bondioli, T. Manfredini, G. C. Pellacani, Interceram. 48 (1999) 414-242.

[8] M. A. Abreu, S. M. Toffoli, Anais do $46^{\circ}$ Congresso Brasileiro de Cerâmica, S. Paulo, SP (2002) 1281-1292.

[9] K. W. Milanez, Incorporação de resíduo de galvanoplastia na produção de pigmentos inorgânicos, Dissertação de Mestrado, Universidade Federal de Santa Catarina, Florianópolis, SC (2003) 75 p.

[10] F. P. Glasser, Am. Mineral. 44 (1959) 1301-1303.

[11] A. S. Bystrikov, Y. F. Petrov, Steklo i Keramica 8 (1968) 31-32.

[12] J. Alarcon, P. Escribano, J. J. Gargallo, Br. Ceram. Trans. J. 83 (1984) 81-83.

[13] J. Carda, G. Monros, P. Escribano, Bol. Soc. Ceram. Vidr. 28 (1989) 15-21.

[14] J. Carda, G. Monros, P. Escribano, J. Am. Ceram. Soc. 72 (1989) 160-162.

[15] J. Carda, M. C. Martí, E. Conrdoncillo, P. Escribano, Bol. Soc. Esp. Ceram. Vidr. 31 (1992) 19-31.

[16] M. Llusar, J. A. Badenes, P. Escribano, G. Monrós, Key Eng. Mater. 132-136 (1997) 2236-2239.

[17] T. Isaacs, Nature 4887 (1963) 1291.

[18] ABNT, NBR 10005, Lixiviação de resíduos, procedimento (1987).

[19] ABNT, NBR 10004, Resíduos sólidos, classificação (1987).

[20] ABNT, NBR 10006, Solubilização de resíduos sólidos, procedimento (1987).

[21] F. A. Hummel, Am. Mineral. 35 (1950) 324-325.

[22] M. Llusar, J. A. Badenes, J. Calbo, M. A. Tena, G. Monrós, Am. Ceram. Soc. Bull. 77 (1999) 63-68.

[23] R. Stefani, Pigmentos cerâmicos de cromo-estanho, Tese de Doutorado, Universidade Federal de S. Carlos, SP (1997) $104 \mathrm{p}$.

(Rec.01/10/2004, Rev. 19/11/2004, Ac. 13/02/2005) 